University of Nebraska - Lincoln

DigitalCommons@University of Nebraska - Lincoln

\title{
Larval mortality and development for rotation-resistant and rotation-susceptible populations of western corn rootworm on $\mathrm{Bt}$ corn
}

N A. Tinsley

University of Illinois, tinsley@illinois.edu

J L. Spencer

Illinois Natural History Survey, Prairie Research Institute, University of Illinois

RE. Estes

Department of Crop Sciences, University of Illinois

J. R. Prasifka

USDA ARS Northern Crop Science Laboratory, prasifka@illinois.edu

P M. Schrader

Department of Crop Sciences, University of Illinois

See next page for additional authors

Follow this and additional works at: https://digitalcommons.unl.edu/usdaarsfacpub

Part of the Other Environmental Sciences Commons

Tinsley, N A.; Spencer, J L.; Estes, R E.; Prasifka, J. R.; Schrader, P M.; French, B. W.; and Gray, M E., "Larval mortality and development for rotation-resistant and rotation-susceptible populations of western corn rootworm on Bt corn" (2014). Publications from USDA-ARS / UNL Faculty. 1512.

https://digitalcommons.unl.edu/usdaarsfacpub/1512

This Article is brought to you for free and open access by the U.S. Department of Agriculture: Agricultural Research Service, Lincoln, Nebraska at DigitalCommons@University of Nebraska - Lincoln. It has been accepted for inclusion in Publications from USDA-ARS / UNL Faculty by an authorized administrator of DigitalCommons@University of Nebraska - Lincoln. 


\section{Authors}

N A. Tinsley, J L. Spencer, R E. Estes, J. R. Prasifka, P M. Schrader, B. W. French, and M E. Gray 


\title{
Larval mortality and development for rotation-resistant and rotation-susceptible populations of western corn rootworm on Bt corn
}

\author{
N. A. Tinsley ${ }^{1}$, J. L. Spencer ${ }^{2}$, R. E. Estes ${ }^{1}$, J. R. Prasifka ${ }^{3}$, P. M. Schrader ${ }^{1}$, B. W. French ${ }^{4}$ \& M. E. Gray ${ }^{1}$ \\ 1 Department of Crop Sciences, University of Illinois, Urbana, IL, USA \\ 2 Illinois Natural History Survey, Prairie Research Institute, University of Illinois, Champaign, IL, USA \\ 3 USDA ARS Northern Crop Science Laboratory, Fargo, ND, USA, \\ 4 USDA ARS North Central Agricultural Research Laboratory, Brookings, SD, USA
}

Keywords

Bacillus thuringiensis Berliner, Diabrotica virgifera virgifera LeConte, Zea mays (L.)

\section{Correspondence \\ Nicholas A. Tinsley (corresponding author), Department of Crop Sciences, University of Illinois, 1102 S. Goodwin Ave., Urbana, IL, USA. \\ E-mail: tinsley@illinois.edu}

Received: April 4, 2014; accepted: June 24, 2014.

doi: 10.1111/jen.12149

\begin{abstract}
The western corn rootworm, Diabrotica virgifera virgifera LeConte, is one of the most economically important insect pests threatening the production of corn, Zea mays (L.), in the United States. Throughout its history, this insect has displayed considerable adaptability by overcoming a variety of pest management tactics, including the cultural practice of annual crop rotation. Since first reported in Illinois in the late 1980s, populations of the rotation-resistant western corn rootworm have spread over a wide area of the eastern Corn Belt. Currently, little information is available concerning the interaction of rotation resistance with the use of genetically modified corn expressing insecticidal toxins from Bacillus thuringiensis Berliner (Bt), a popular tactic for preventing larval injury and its associated yield loss. The goal of this greenhouse experiment was to determine whether rotation-resistant and rotation-susceptible western corn rootworm larvae differ with respect to survival or development when exposed to single- or dual-toxin (pyramided) Bt corn. Individual corn plants were infested with 225 near-hatch eggs at the V5 (five leaf collar) growth stage. Larvae developed undisturbed on the root systems for 17 days, after which they were recovered using Berlese-Tullgren funnels. Surviving larvae were counted to estimate mortality, and head capsule widths were measured to assess development. Rotation-resistant and rotationsusceptible larvae had statistically similar mean levels of mortality and head capsule widths when exposed to both single-toxin (Cry3Bbl or Cry34/35Abl) and pyramided (Cry3Bbl+ Cry34/35Abl) Bt corn, suggesting that these two populations do not differ with respect to survival or development when exposed to Bt corn. Additionally, the statistically similar mean levels of mortality for larvae exposed to single-toxin and pyramided Bt corn suggest that pyramided Bt hybrids containing the Cry3Bbl and Cry34/35Abl toxins do not result in additive mortality for western corn rootworm larvae. Implications for management of this economically important pest are discussed.
\end{abstract}

\section{Introduction}

Corn, Zea mays (L.), is an important grain crop cultivated globally for a variety of uses. The United States accounted for approximately $37 \%$ of the $9.6 \times 10^{11} \mathrm{~kg}$ of corn produced globally in 2013 (USDA FAS [United States Department of Agriculture Foreign Agricultural Service] 2014). One of the most 
economically important insect pests threatening corn production in the United States is the western corn rootworm (Diabrotica virgifera virgifera LeConte) (Coleoptera: Chrysomelidae). Yield losses and control costs associated with corn rootworm species - which also include the northern (Diabrotica barberi Smith \& Lawrence) and southern (Diabrotica undecimpunctata howardi Barber) corn rootworms - exceed \$1 billion annually in the United States (Metcalf 1986). Western corn rootworm larvae feed on the root tissue of corn plants, which can result in impaired photosynthesis (Godfrey et al. 1993; Riedell and Reese 1999), reduced uptake of water (Godfrey et al. 1993) and nitrogen (Spike and Tollefson 1989); colonization by phytopathogenic or saprophytic fungi (Bryson et al. 1953; Kurtz et al. 2010) and plant lodging (Spike and Tollefson 1991). Although yield loss due to root injury is highly variable (Gray and Steffey 1998), Tinsley et al. (2013) estimated that for every node (i.e. circle of roots) consumed by corn rootworm larvae, a yield loss of approximately 15\% can be expected.

Throughout its pest history, the western corn rootworm has demonstrated a high degree of adaptability, as it has overcome a variety of pest management strategies (Gray et al. 2009). This insect has evolved resistance or reduced susceptibility to carbamate (Meinke et al. 1998), organophosphate (Ball 1968; Call et al. 1977; Meinke et al. 1998) and organochlorine (Ball and Weekman 1962; Hamilton 1965) insecticides. Annual crop rotation (rotating corn with a non-host crop) was highly effective for managing the western corn rootworm since it was first recommended in the early 1900s (Gillette 1912). However, much of the east-central Corn Belt now hosts a variant western corn rootworm with resistance to crop rotation (Levine et al. 2002). Additionally, fieldevolved resistance to genetically modified corn expressing an insecticidal toxin (Cry3Bbl) from Bacillus thuringiensis Berliner (Bt) has been confirmed for this insect (Gassmann et al. 2011). Unfortunately, little information is available concerning the potential interaction of rotation-resistant populations of the western corn rootworm with alternate management tactics. One example of this type of interaction is the relative effectiveness of $\mathrm{Bt}$ toxins against rotationresistant and rotation-susceptible populations of the western corn rootworm. Understanding this type of interaction may allow applied entomologists to refine management recommendations.

Gray et al. (2007) evaluated a number of Bt hybrids targeting the western corn rootworm - all hybrids expressed the same Bt toxin (Cry3Bbl), which was inserted using the same transgenic event
(MON-ØØ863-5, Monsanto Co., St. Louis, MO). During 1 year of their experiment (2006), two trial sites were evaluated (Monmouth and Urbana, IL). Urbana is located in a region of Illinois that has historically had high populations of the rotation-resistant western corn rootworm. However, at Monmouth, the likelihood of a large rotation-resistant population of this pest was much lower in 2006. Although root injury for the non-Bt untreated check was similar at both locations, root injury for the Bt hybrids was approximately $105 \%$ greater at the Urbana site. The authors hypothesized that rotation-resistant and rotationsusceptible larvae may differ in their capacity to injure Bt roots. However, the experimental design used by Gray et al. (2007) was not constructed in a manner that could test this hypothesis explicitly - Bt hybrids at Monmouth and Urbana may have been subjected to feeding by both rotation-resistant and rotation-susceptible larvae in unknown proportions. The goal of the greenhouse experiment described here was to determine whether rotation-resistant and rotationsusceptible western corn rootworm larvae differ with respect to survival or development when exposed to corn expressing Bt toxins. A single-plant bioassay was used with techniques adapted from Gassmann et al. (2011).

\section{Materials and Methods}

\section{Experimental design}

This experiment was conducted during 2012 and 2013 using a two-way factorial arrangement in a completely randomized design. The first factor was western corn rootworm population and included two levels: (i) rotation resistant and (ii) rotation susceptible. This first factor is hereafter referred to as 'population'. Larvae from each population were evaluated for survival and development on five corn hybrids, including a hybrid expressing Cry34/35Abl (Event DAS-59122-7, Pioneer 34P94, DuPont Pioneer, Johnston, IA), its near-isoline (Pioneer 34P89, DuPont Pioneer), a hybrid expressing Cry3Bbl (Event MON88Ø17-3, DKC61-19, Monsanto Co., St. Louis, MO), its near-isoline (DKC61-22, Monsanto Co.), and a hybrid expressing both Cry3Bbl and Cry34/35Abl (Events MON-88Ø17-3 and DAS-59122-7, DKC6121, Monsanto Co.) - DKC61-19 and DKC61-21 shared a common near-isoline (DKC61-22). This second factor is hereafter referred to as 'treatment'. In total, three runs of this experiment were performed. For each run, four replications of each population $\times$ treatment combination were used. 


\section{Seed preparation and planting information}

All seed used during this experiment was treated with a neonicotinoid insecticidal seed treatment (either clothianidin or thiamethoxam) at $0.25 \mathrm{mg}$ active ingredient/seed. These insecticidal treatments were removed because the primary focus of this experiment was to examine mortality caused by the Bt toxins being evaluated. Seeds were first placed in a $1 \%$ detergent solution (Dawn Ultra Concentrated Dish Soap, Proctor \& Gamble, Cincinnati, $\mathrm{OH}$ ) and agitated gently for $20 \mathrm{~min}$. Following agitation, the seeds were rinsed thoroughly under running water. This wash/ rinse procedure was repeated for a total of three cycles. Washed seeds were allowed to dry for $12 \mathrm{~h}$, after which they were soaked in a $10 \%$ bleach solution (Clorox Regular Bleach, The Clorox Co., Oakland, CA). While soaking in the bleach solution, the seeds were stirred periodically. After soaking for approximately $\mathrm{l} \mathrm{h}$, the seeds were rinsed thoroughly under running water and allowed to dry for at least $24 \mathrm{~h}$ prior to planting.

This experiment was conducted at the Natural Resources Studies Annex greenhouse on the University of Illinois campus in Champaign, IL. The greenhouse was maintained at $25^{\circ} \mathrm{C}$ with $16 \mathrm{~h}$ of light each day. For each run, 40 single-plant pots were prepared (2 populations $\times 5$ hybrids $\times 4$ replications/run) . Pots were made of white polypropylene and had a volume of $950 \mathrm{ml}$ (Item No. 81144 , US Plastic Corp., Lima, $\mathrm{OH})$. Four 3-mm holes were drilled into the bottom of each pot for drainage. The pots were then filled with $750 \mathrm{ml}$ of a 1 : 1 mixture of potting soil (Sunshine Mix LC1, Sun Gro Horticulture Canada Ltd., Vancouver, BC) and sterilized topsoil. Prior to planting the seeds, each pot was fertilized with $4 \mathrm{~g}$ of a 14-14-14 (N-P-K) slow-release fertilizer (Osmocote Smart-Release Plant Food, The Scotts Miracle-Gro Co., Marysville, $\mathrm{OH})$. A single seed was planted in the centre of each pot at a depth of $1 \mathrm{~cm}$. Pots were watered as needed to maintain a uniform level of moisture, with a maximum of $50 \mathrm{ml}$ of water per day. Periodically, all of the plants were trimmed so that their overall height did not exceed $30 \mathrm{~cm}$ - trimming the plants reduced their overall water requirement and helped maintain consistent moisture.

\section{Egg preparation and infestation technique}

The western corn rootworm eggs used during this experiment were provided by the USDA ARS North Central Agricultural Research Laboratory (NCARL) at Brookings, SD. The rotation-resistant and rotation-susceptible populations were identified as 'Spencer' (initially collected from Illinois, in culture since 2010) and 'Whitlock' (initially collected from South Dakota, in culture since 1996), respectively (C. N. Nielson, USDA ARS NCARL, personal communication). Upon receipt, the eggs and their soil matrix were soaked in water for approximately $30 \mathrm{~min}$. To separate eggs from the soil, the solution was poured through a stainless steel mesh sieve with 250- $\mu$ m pores. The eggs were rinsed under running water for 5 min to remove all soil. The eggs were then placed into a 950-ml container filled with $750 \mathrm{ml}$ of water. We used water as a medium for post-diapause egg development because previous attempts using moist soil resulted in excessive fungal growth and reduced egg viability. The eggs were examined regularly to monitor their development. To prevent fungal growth in the egg containers, approximately $75 \%$ of the water was replaced daily. Eggs were ready to hatch (i.e. neonate larvae were visible within the eggs) after approximately 21 days of storage at room temperature.

Infestation of greenhouse plants by near-hatch eggs was timed to coincide with the V5 (five leaf collar) growth stage. For each plant, 225 eggs (measured volumetrically) were transferred from the egg containers into a $1.5-\mathrm{ml}$ microcentrifuge tube. To infest each plant, a 10-cm-long hole was bored into the soil approximately $2.5 \mathrm{~cm}$ from the base of the plant. The pre-measured volume of eggs was transferred from the microcentrifuge tube to the hole using a plastic pipette. After depositing the eggs, the infestation site was closed by gently pinching together the surface of the soil near the top of the hole. Larvae were allowed to develop undisturbed on each plant for $17 \mathrm{~d}$ - Gassmann et al. (2011) noted that this duration was sufficient to allow the fastest developing larvae to reach the final developmental stage (instar) prior to pupation.

\section{Larval extraction and processing}

To extract larvae from each pot, plants were cut near the soil surface and the pots were transported to the Agricultural Engineering Farm near Urbana, IL. The contents of each pot (soil and root tissue) were gently removed and placed onto a square piece of aluminium screen $\left(20 \mathrm{~cm}\right.$ on each side) with 45 holes $/ \mathrm{cm}^{2}$. This screen was then placed into the upper chamber of a collapsible Berlese-Tullgren funnel trap (Item No. 2832; BioQuip Products Inc., Rancho Dominguez, CA). These traps are commonly used to extract insects and other arthropods from leaf litter or soil and 
operate by utilizing a heat source placed above the sample to stimulate mobile organisms to move away from the heat and towards a collection container at the bottom of the trap. For this experiment, the collection container was a Whirl-Pak bag (Item No. $1114 \mathrm{~B}$, BioQuip Products Inc.) filled with $50 \mathrm{ml}$ of $85 \%$ ethanol, and the heat source was a $40 \mathrm{~W}$ incandescent light bulb. Larvae were extracted continuously for a period of $72 \mathrm{~h}$, after which the number of larvae present in each sample was recorded.

From each sample, a subsample of three larvae was selected at random for head capsule measurement. Western corn rootworm larvae develop through three instars - these developmental stages can be differentiated by measuring the width of their head capsule. First, second and third instar larvae have head capsule widths measuring within the ranges of $0-270,270-$ 410 and 410-580 $\mu \mathrm{m}$, respectively (Hammack et al. 2003). Head capsule widths were determined for each larva by measuring the widest portion of the head. A dissecting microscope (Model MZ125, Leica Microsystems Inc., Buffalo Grove, IL) with an ocular reticle was used - a magnification of $10 \mathrm{X}$ was selected to achieve an accuracy of $10 \mu \mathrm{m}$.

\section{Statistical analysis}

To standardize comparisons between western corn rootworm populations, the relative corrected mortality for each Bt sample was determined using formulae adapted from Abbott (1925). This metric is 'relative' because it is calculated for each population independently and 'corrected' because it accounts for natural mortality not caused by exposure to Bt toxins. First, the proportional survival for each sample was calculated using the formula:

$$
s_{\mathrm{ti}}=\frac{l_{\mathrm{ti}}}{r}
$$

Where $s_{\mathrm{ti}}$ was the proportional survival for sample $i$ of treatment $\mathrm{t}, l_{\mathrm{ti}}$ was the number of larvae recovered from sample $i$ of treatment $t$, and $r$ was the infestation rate. Next, the mean proportional survival for each near-isoline treatment for each population was calculated using the formula:

$$
\bar{s}_{t}=\left(\sum_{i=1}^{n_{t}} s_{\mathrm{ti}}\right) \div n_{t}
$$

where $\bar{s}_{t}$ was the mean proportional survival for near-isoline treatment $t, s_{\mathrm{ti}}$ was the proportional survival for sample $i$ of near-isoline treatment $t$, and $n_{t}$ was the total number of samples for near-isoline treatment $t$. Finally, the corrected mortality for each sample of the Bt treatments for each population was calculated using the formula:

$$
m_{\mathrm{ti}}=\frac{\bar{s}_{t}-s_{\mathrm{ti}}}{\bar{s}_{t}}
$$

where $m_{\mathrm{ti}}$ was the corrected mortality for sample $i$ of Bt treatment $t, \bar{s}_{t}$ was the mean proportional survival for near-isoline treatment $t$, and $s_{\mathrm{ti}}$ was the proportional survival for sample $i$ of Bt treatment $t$.

Response variables (proportional survival for nearisoline treatments, relative corrected mortality for $\mathrm{Bt}$ treatments and head capsule widths) were analysed using SAS 9.2 (SAS Institute Inc., Cary, NC). To stabilize variances and meet the assumptions of analysis of variance, response variables were analysed using a square-root transformation. Statistical tests for fixed effects were performed using PROC MIXED. Fixed effects included population, treatment, and their interaction and were declared significant at $\mathrm{P} \leq 0.05$. Means were compared using the LSMEANS option of PROC MIXED and were declared significantly different at $\mathrm{P} \leq 0.05$.

\section{Results}

Because a significant interaction effect was never documented for any response variable, means are only presented for main effects. Mean proportional survival was only analysed for near-isoline treatments. A significant effect of population on mean proportional survival was observed (table 1), with rotation-resistant larvae averaging a $14.0 \%$ greater level of proportional survival than rotation-susceptible larvae (table 2). No significant effect of treatment on mean proportional survival was observed (table 1), indicating that mean proportional survival was similar for both near-isoline treatments (table 2).

No significant effect of population, treatment, or their interaction was observed for mean relative corrected mortality for Bt treatments (table 1 ). With respect to the effect of population, mean relative corrected mortality levels for both rotation-resistant and rotation-susceptible larvae differed by less than 3.0\% and were statistically similar (table 3 ). For the effect of treatment, mean relative corrected mortality levels ranged from 68.8 to $71.8 \%$ and were statistically similar across all Bt treatments, including the Cry3Bbl + Cry34/35Abl dual-toxin treatment (table 3). 
Table 1 Statistical tests ${ }^{1}$ of fixed effects for response variables analysed

\begin{tabular}{llllll}
\hline Response variable & Effect $^{2}$ & $d f_{N}$ & $d f_{D}$ & \multicolumn{1}{l}{$F$} & \multicolumn{1}{c}{$P$} \\
\hline Proportional survival & Population & 1 & 2 & 39.2 & 0.02 \\
for near-isoline & Treatment & 1 & 2 & 1.3 & 0.37 \\
treatments & $\begin{array}{l}\text { Population } \times \\
\text { treatment }\end{array}$ & 1 & 2 & 4.2 & 0.18 \\
& Population & 1 & 2 & 1.4 & 0.36 \\
Relative corrected & Treatment & 2 & 4 & 0.3 & 0.74 \\
mortality for Bt & Population $\times$ & 2 & 4 & 0.5 & 0.62 \\
treatments & treatment & & & & \\
& Population & 1 & 2 & 2.0 & 0.30 \\
Head capsule widths & Treatment & 4 & 8 & 12.1 & $<0.01$ \\
& Population $\times$ & 4 & 8 & 3.0 & 0.09 \\
& treatment & & & &
\end{tabular}

${ }^{1}$ Statistical tests were performed using PROC MIXED of SAS 9.2. Data were analysed using a square-root transformation.

${ }^{2}$ Effects were declared significant at $P \leq 0.05$.

Table 2 Mean $^{1}$ proportional survival for near-isoline treatments for the effects of population and treatment

\begin{tabular}{lll}
\hline Effect & Level & $\begin{array}{l}\text { Proportional } \\
\text { survival (\%) }\end{array}$ \\
\hline Population & Rotation resistant & $52.7 \mathrm{a}$ \\
& Rotation susceptible & $38.7 \mathrm{~b}$ \\
Treatment & Cry3Bb1 near-isoline & $46.5 \mathrm{a}$ \\
& Cry34/35Ab1 near-isoline & $44.8 \mathrm{a}$ \\
\hline
\end{tabular}

${ }^{1}$ Mean comparisons were made using PROC MIXED of SAS 9.2. Means within a column for an individual effect that share a similar letter do not differ significantly $(P \leq 0.05)$. Data were analysed using a square-root transformation; actual means are reported.

${ }^{2}$ Proportional survival represents the number of larvae recovered divided by the infestation rate (225 eggs/plant).

Table 3 Mean $^{1}$ relative corrected mortality for Bt treatments for the effects of population and treatment

\begin{tabular}{lll}
\hline Effect & Level & $\begin{array}{l}\text { Relative corrected } \\
\text { mortality (\%) }\end{array}$ \\
\hline Population & Rotation resistant & $68.5 \mathrm{a}$ \\
& Rotation susceptible & $71.4 \mathrm{a}$ \\
Treatment & Cry3Bb1 & $68.8 \mathrm{a}$ \\
& Cry34/35Ab1 & $69.3 \mathrm{a}$ \\
& Cry3Bb1+Cry34/35Ab1 & $71.8 \mathrm{a}$ \\
\hline
\end{tabular}

${ }^{1}$ Mean comparisons were made using PROC MIXED of SAS 9.2. Means within a column for an individual effect that share a similar letter do not differ significantly $(P \leq 0.05)$. Data were analysed using a square-root transformation; actual means are reported.

${ }^{2}$ Relative corrected mortality represents the mortality caused by the Bt treatments corrected for natural mortality relative to each population.
Only the effect of treatment on mean head capsule width was statistically significant - the effect of population and the interaction of population and treatment were not (table 1). With respect to the effect of population, mean head capsule widths for rotation-resistant and rotation-susceptible larvae differed by only $5 \mu \mathrm{m}$ and were statistically similar (table 4). For the effect of treatment, mean head capsule widths for larvae on near-isoline treatments were significantly greater than mean head capsule widths for larvae on Bt treatments (table 4). Additionally, no significant differences were observed in mean head capsule widths between the near-isoline treatments or among the various Bt treatments (table 4).

\section{Discussion}

Proportional survival of larvae for near-isoline treatments was analysed to determine whether the level of natural mortality differed between the two populations of western corn rootworm evaluated during this experiment. Determining proportional survival for each population was necessary to standardize comparisons of mortality caused by treatments containing Bt toxins. Because proportional survival between rotation-resistant and rotation-susceptible larvae differed significantly (table 2 ), the decision to use a relative parameter to analyse corrected mortality caused by the Bt toxins was justified. It is unclear why these two populations differed with respect to proportional survival on near-isoline treatments. The rotation-resistant population was represented by the Spencer colony, which has been in culture since 2010 (ca. 2 generations). In contrast, the Whitlock colony was

Table 4 Mean $^{1}$ head capsule widths for the effects of population and treatment

\begin{tabular}{lll}
\hline Effect & Level & $\begin{array}{l}\text { Head capsule } \\
\text { width }(\mu \mathrm{m})\end{array}$ \\
\hline Population & Rotation resistant & $245 \mathrm{a}$ \\
& Rotation susceptible & $240 \mathrm{a}$ \\
Treatment & Cry3Bb1 & $227 \mathrm{~b}$ \\
& Cry3Bb1 near-isoline & $264 \mathrm{a}$ \\
& Cry34/35Ab1 & $235 \mathrm{~b}$ \\
& Cry34/35Ab1 near-isoline & $265 \mathrm{a}$ \\
& Cry3Bb1+Cry34/35Ab1 ${ }^{2}$ & $222 \mathrm{~b}$
\end{tabular}

${ }^{1}$ Mean comparisons were made using PROC MIXED of SAS 9.2. Means within a column for an individual effect that share a similar letter do not differ significantly $(P \leq 0.05)$. Data were analysed using a square-root transformation; actual means are reported.

${ }^{2}$ The near-isoline for this dual-toxin treatment was the Cry3Bb1 near-isoline. 
used to represent the rotation-susceptible population this colony has been in culture since 1996 (ca. 16 generations). Although the duration of time spent in culture between these two colonies varies substantially, it is unlikely that this difference contributed to the observed difference in proportional survival. Kim et al. (2007) used microsatellite loci to compare genetic diversity among various colonies maintained at USDA ARS NCARL (including some wild-type populations as well). Their findings demonstrated that western corn rootworm colonies maintained in culture for up to 22 generations could not be differentiated from wild-type populations based on genetic diversity.

One of the principal benefits associated with $\mathrm{Bt}$ corn is its demonstrated ability to cause substantial mortality among western corn rootworm larvae (Storer et al. 2006; Hibbard et al. 2010). During this experiment, relative corrected mortality was analysed to determine whether rotation-resistant and rotationsusceptible larvae differed with respect to survival on Bt corn. While the levels of mortality due to Bt toxin exposure observed in this experiment may appear lower than expected (68.8-71.8 for the various Bt treatments, table 3), they are not out of the range of what has been reported previously (as summarized by Gassmann 2012). Of primary interest is how our results compare with those of Gassmann et al. (2011), as our techniques were modelled after their methods. For the offspring of beetles collected from their 'control' fields (i.e. areas without western corn rootworm populations suspected to be resistant to Cry3Bbl), Gassmann et al. (2011) reported levels of mortality ranging from 68 to $94 \%$ or 75 to $100 \%$ when exposed to Cry3Bbl- or Cry34/35Abl-expressing corn, respectively. Because the levels of mortality we observed are very near the ranges reported by Gassmann et al. (2011), we feel that our data are of sufficient quality to draw meaningful conclusions. The lack of a significant effect of population on relative corrected mortality (table 3 ) suggests that mortality caused by the Bt toxins evaluated during this experiment (Cry3Bbl and Cry34/35Abl) does not differ between rotationresistant and rotation-susceptible larvae. Additionally, no significant effect of treatment on relative corrected mortality was observed - larvae experienced similar levels of mortality when exposed to either single- or dual-toxin (i.e. pyramided) Bt corn (table 3). This observation suggests that larval mortality caused by each of the toxins expressed in the pyramided treatment was non-additive.

The demonstration of non-additive larval mortality associated with the pyramided treatment may have implications for integrated resistance management. Onstad and Meinke (2010) suggested that the evolution of resistance to Bt corn by the western corn rootworm would be delayed if a pyramided, multipletoxin strategy was adopted over a single-toxin approach. However, Onstad et al. (2011) questioned the value of a pyramided strategy for integrated resistance management if multiple-toxin Bt corn failed to increase mortality in the target pest when compared with single-toxin $\mathrm{Bt}$ corn. Recent estimates suggest that mortality caused by one such pyramided product - marketed as Genuity SmartStax (Monsanto Co.) or SmartStax (Dow AgroSciences LLC, Indianapolis, IN) - is not substantially greater than either of its constituent single toxins (Cry34/35Abl and Cry3Bbl) (USEPA OPPTS [United States Environmental Protection Agency Office of Prevention, Pesticides, and Toxic Substances] 2011). Results from a field experiment evaluating adult emergence summarized by Head et al. (2014) support this conclusion as well. When averaged across sites, survivorship was $3.3872 \%$ and $1.6573 \%$ for the single-toxin treatments DAS-59122-7 (Cry34/35Abl) and MON-88Ø17-3 (Cry3Bbl), respectively (values derived from table 6 of Head et al. 2014). Survivorship for the dual-toxin treatment DAS-59122-7 × MON-88Ø17-3 (Cry34/ $35 \mathrm{Abl}+\mathrm{Cry3Bbl)}$ was $1.0699 \%$ when averaged across sites, which does not appear to be substantially lower than survivorship for the single-toxin treatment MON-88Ø17-3.

Many experiments have documented delayed emergence of western corn rootworm adults when exposed to Bt corn (Storer et al. 2006; Murphy et al. 2010; Spencer et al. 2012), which has generally been attributed to slower than typical larval development. Larval head capsule widths were evaluated for a subsample of all larvae recovered during this experiment to determine whether rotation-resistant and rotationsusceptible larvae differed with respect to development on Bt corn. Mean head capsule widths were greatest for larvae on near-isoline treatments (table 4). This observation agrees with results presented by Hibbard et al. (2010), which demonstrated that larvae exposed to non-Bt corn typically had greater head capsule widths than those exposed to Bt corn. Mean head capsule widths for larvae from both populations were statistically similar (table 4), indicating that larvae from these two populations develop similarly when exposed to the treatments evaluated during this experiment.

Based on the results of their field experiment, Gray et al. (2007) hypothesized that rotation-resistant western corn rootworm larvae may cause more injury 
to Bt corn than rotation-susceptible larvae. During this experiment, mortality and development were evaluated for larvae from rotation-resistant and rotation-susceptible populations. Because mean relative corrected mortality levels and head capsule widths were similar for both rotation-resistant and rotationsusceptible larvae, as well as a documented lack of any significant interaction between the effects of population and treatment for the response variables analysed, we conclude that any hypothesized difference in the ability of these two populations to injure roots expressing one or more $\mathrm{Bt}$ toxins is unrelated to survival or development.

The fundamental difference between rotationresistant and rotation-susceptible populations of the western corn rootworm is the loss of ovipositional fidelity to cornfields among rotation-resistant females (Rondon and Gray 2004), which Pierce and Gray (2006) attributed to long term, strict annual rotation of corn and soya bean. To date, the use of genetic techniques to differentiate between rotation-resistant and rotation-susceptible beetles has been unsuccessful (Miller et al. 2006). However, Garabagi et al. (2008) noted that expression of cyclic GMP-dependent protein kinases is $25 \%$ greater in rotation-resistant females when compared with rotation-susceptible females. Genes for these proteins have been implicated in the regulation of behaviour in many animals. Recently, Curzi et al. (2012) reported that digestive enzymes play a role in facilitating rotation resistance. The authors noted that rotation-resistant females had increased constitutive expression of cathepsin L-like proteases, allowing them to overcome soya bean defences (cysteine protease inhibitors) and forage for a longer duration in soya bean than rotation-susceptible females. Apparently, adaptive changes in rotationresistant adult behaviour or physiology have no correlation with the capacity of larvae to injure corn roots.

However, this greenhouse experiment focused on western corn rootworm larval survival and development, not potential to injure corn roots. Although no significant differences in survival or development on Bt corn between rotation-resistant and rotation-susceptible larvae were documented, other factors should be explored prior to concluding that no difference in capacity to injure corn roots exists between these two populations. One such example may be behavioural differences in root feeding. Clark et al. (2006) noted that western corn rootworm larvae exposed to Bt corn display two types of feeding behaviour - sedentary or roaming. Their findings suggest that larval feeding behaviour associated with exposure to $\mathrm{Bt}$ corn is complex. Further research may be needed to identify whether other factors may contribute to a potential difference in the capacity to injure corn roots between rotation-resistant and rotation-susceptible larvae.

\section{Acknowledgements}

We thank everyone who assisted with trial establishment and maintenance, including Caitlin Allen, Shane Bailey, Daniel Fulton and Andrew Morehouse. We extend our gratitude to Chad Nielson of the USDA ARS North Central Agricultural Research Laboratory for coordinating the delivery of western corn rootworm eggs used for this experiment. We thank the helpful personnel of the Turner Hall greenhouse and Natural Resources Studies Annex greenhouse. Seed was provided by Monsanto Co. and DuPont Pioneer. Funding for this experiment was provided by the Insect Management and Insecticide Evaluation Program of the University of Illinois and the Pioneer Crop Management Research Awards Program (DuPont Pioneer).

\section{References}

Abbott WS, 1925. A method of computing the effectiveness of an insecticide. J. Econ. Entomol. 18, 265-267.

Ball HJ, 1968. A five-year study of potential western corn rootworm resistance to diazinon and phorate in Nebraska. J. Econ. Entomol. 61, 496-498.

Ball HJ, Weekman GT, 1962. Insecticide resistance in the adult western corn rootworm in Nebraska. J. Econ. Entomol. 55, 439-441.

Bryson HR, Wilbur DA, Burkhardt CC, 1953. The western corn rootworm, Diabrotica virgifera Lec. in Kansas. J. Econ. Entomol. 46, 995-999.

Call DJ, Walgenbach DD, Sutter GR, 1977. Corn rootworm cholinesterase activity as influenced by species, sex, age, and cold storage. J. Econ. Entomol. 70, 533-535.

Clark PL, Vaughn TT, Meinke LJ, Molina-Ochoa J, Foster JE, 2006. Diabrotica virgifera virgifera (Coleoptera: Chrysomelidae) larval feeding behavior on transgenic maize (MON 863) and its isoline. J. Econ. Entomol. 99, $722-727$.

Curzi MJ, Zavala JA, Spencer JL, Seufferheld MJ, 2012. Abnormally high digestive enzyme activity and gene expression explain the contemporary evolution of a $D i$ abrotica biotype able to feed on soybeans. Ecol. Evol. 2, 2005-2017.

Garabagi F, French BW, Schaafsma AW, Pauls KP, 2008. Increased expression of a cGMP-dependent protein kinase in rotation-adapted western corn rootworm 
(Diabrotica virgifera virgifera L.). Insect Biochem. Mol. Biol. 38, 697-704.

Gassmann AJ, 2012. Field-evolved resistance to Bt maize by western corn rootworm: predictions from the laboratory and effects in the field. J. Invertebr. Pathol. 110, 287-293.

Gassmann AJ, Petzold-Maxwell JL, Keweshan RS, Dunbar MW, 2011. Field-evolved resistance to Bt maize by western corn rootworm. PLoS ONE 6, E22629.

Gillette CP, 1912. Diabrotica virgifera Lec. as a corn rootworm. J. Econ. Entomol. 5, 364-366.

Godfrey LD, Meinke LJ, Wright RJ, 1993. Effects of larval injury by western corn rootworm (Coleoptera: Chrysomelidae) on gas exchange parameters of field corn. J. Econ. Entomol. 86, 1546-1556.

Gray ME, Steffey KL, 1998. Corn rootworm (Coleoptera: Chrysomelidae) larval injury and root compensation of 12 maize hybrids: an assessment of the economic injury index. J. Econ. Entomol. 91, 723-740.

Gray ME, Steffey KL, Estes RE, Schroeder JB, 2007. Responses of transgenic maize hybrids to variant western corn rootworm larval injury. J. Appl. Entomol. 131, 386-390.

Gray ME, Sappington TW, Miller NJ, Moeser J, Bohn MO, 2009. Adaptation and invasiveness of western corn rootworm: intensifying research on a worsening pest. Annu. Rev. Entomol. 54, 303-321.

Hamilton EW, 1965. Aldrin resistance in corn rootworm beetles. J. Econ. Entomol. 58, 297-300.

Hammack L, Ellsbury MM, Roehrdanz RL, Pikul JL Jr, 2003. Larval sampling and instar determination in field populations of northern and western corn rootworm (Coleoptera: Chrysomelidae). J. Econ. Entomol. 96, 1153-1159.

Head G, Carroll M, Clark T, Galvan T, Huckaba RM, Price P, Samuel L, Storer NP, 2014. Efficacy of SmartStax ${ }^{\circledR}$ insect-protected corn hybrids against corn rootworm: the value of pyramiding the Cry3Bbl and Cry34/35Abl proteins. Crop Prot. 57, 38-47.

Hibbard BE, Clark TL, Ellersieck MR, Meihls LN, El Khishen AA, Kaster V, Steiner H, Kurtz R, 2010. Mortality of western corn rootworm larvae on MIR604 transgenic maize roots: field survivorship has no significant impact on survivorship of F1 progeny on MIR604. J. Econ. Entomol. 103, 2187-2196.

Kim SK, French BW, Sumerford DV, Sappington TW, 2007. Genetic diversity in laboratory colonies of western corn rootworm (Coleoptera: Chrysomelidae), including a nondiapause colony. Environ. Entomol. 36, 637-645.

Kurtz B, Karlovsky P, Vidal S, 2010. Interaction between western corn rootworm (Coleoptera: Chrysomelidae) larvae and root-infecting Fusarium verticillioides. Environ. Entomol. 39, 1532-1538.

Levine E, Spencer JL, Isard SA, Onstad DW, Gray ME, 2002. Adaptation of the western corn rootworm to crop rotation: evolution of a new strain in response to a management practice. Am. Entomol. 48, 94-107.

Meinke LJ, Siegfried BD, Wright RJ, Chandler LD, 1998. Adult susceptibility of Nebraska western corn rootworm (Coleoptera: Chrysomelidae) populations to selected insecticides. J. Econ. Entomol. 91, 594-600.

Metcalf RL, 1986. Foreword. In: Methods for the Study of Pest Diabrotica. Ed. by Krysan JL, Miller TA. Springer, New York, NY, pp. vii-Xv.

Miller NJ, Kim KS, Ratcliffe ST, Estoup A, Bourguet D, Guillemaud T, 2006. Absence of genetic divergence between western corn rootworms (Coleoptera: Chrysomelidae) resistant and susceptible to control by crop rotation. J. Econ. Entomol. 99, 685-690.

Murphy AF, Ginzel MD, Krupke CH, 2010. Evaluating western corn rootworm (Coleoptera: Chrysomelidae) emergence and root damage in a seed mix refuge. J. Econ. Entomol. 103, 147-157.

Onstad DW, Meinke LJ, 2010. Modeling evolution of Diabrotica virgifera virgifera (Coleoptera: Chrysomelidae) to transgenic corn with two insecticidal traits. J. Econ. Entomol. 103, 849-860.

Onstad DW, Mitchell PD, Hurley TM, Lundgren JG, Porter RP, Krupke CH, Spencer JL, DiFonzo CD, Baute TS, Hellmich RL, Buschman LL, Hutchison WD, Tooker JF, 2011. Seeds of change: corn seed mixtures for resistance management and integrated pest management. J. Econ. Entomol. 104, 343-352.

Pierce CMF, Gray ME, 2006. Western corn rootworm, Diabrotica virgifera virgifera LeConte (Coleoptera: Chrysomelidae), oviposition: a variant's response to maize phenology. Environ. Entomol. 35, 423-434.

Riedell WE, Reese RN, 1999. Maize morphology and shoot $\mathrm{CO}_{2}$ assimilation after root damage by western corn rootworm larvae. Crop Sci. 39, 1332-1340.

Rondon SI, Gray ME, 2004. Ovarian development and ovipositional preference of the western corn rootworm (Coleoptera: Chrysomelidae) variant in east central Illinois. J. Econ. Entomol. 97, 390-396.

Spencer J, Onstad D, Krupke C, Hughson S, Pan Z, Stanley B, Flexner L, 2012. Isolated females and limited males: evolution of insect resistance in structured landscapes. Entomol. Exp. Appl. 146, 38-49.

Spike BP, Tollefson JJ, 1989. Relationship of plant phenology to corn yield loss resulting from western corn rootworm (Coleoptera: Chrysomelidae) larval injury, nitrogen deficiency, and high plant density. J. Econ. Entomol. 82, 226-231.

Spike BP, Tollefson JJ, 1991. Yield response of corn subjected to western corn rootworm (Coleoptera: Chrysomelidae) infestation and lodging. J. Econ. Entomol. 84, 1585-1590.

Storer NP, Babcock JM, Edwards JM, 2006. Field measures of western corn rootworm (Coleoptera: Chrysomelidae) mortality caused by Cry34/35Abl proteins expressed in 
maize event 59122 and implications for trait durability. J. Econ. Entomol. 99, 1381-1387.

Tinsley NA, Estes RE, Gray ME, 2013. Validation of a nested error component model to estimate damage caused by corn rootworm larvae. J. Appl. Entomol. 137, 161-169.

USDA FAS [United States Department of Agriculture Foreign Agricultural Service], 2014. World Agricultural
Production (01-14). United States Department of Agriculture, Washington, DC.

USEPA OPPTS [United States Environmental Protection Agency Office of Prevention, Pesticides, and Toxic Substances], 2011. Pesticide Fact Sheet (SmartStax). United States Environmental Protection Agency, Washington, DC. 